\title{
ENTREVISTA COM THOMAS M. ROBINSON PARA A EDIÇÃO COMEMORATIVA DA REVISTA EDUCAÇÃO E FILOSOFIA ${ }^{1}$
}

\section{BREVE APRESENTAÇÃO SOBRE THOMAS M. ROBINSON}

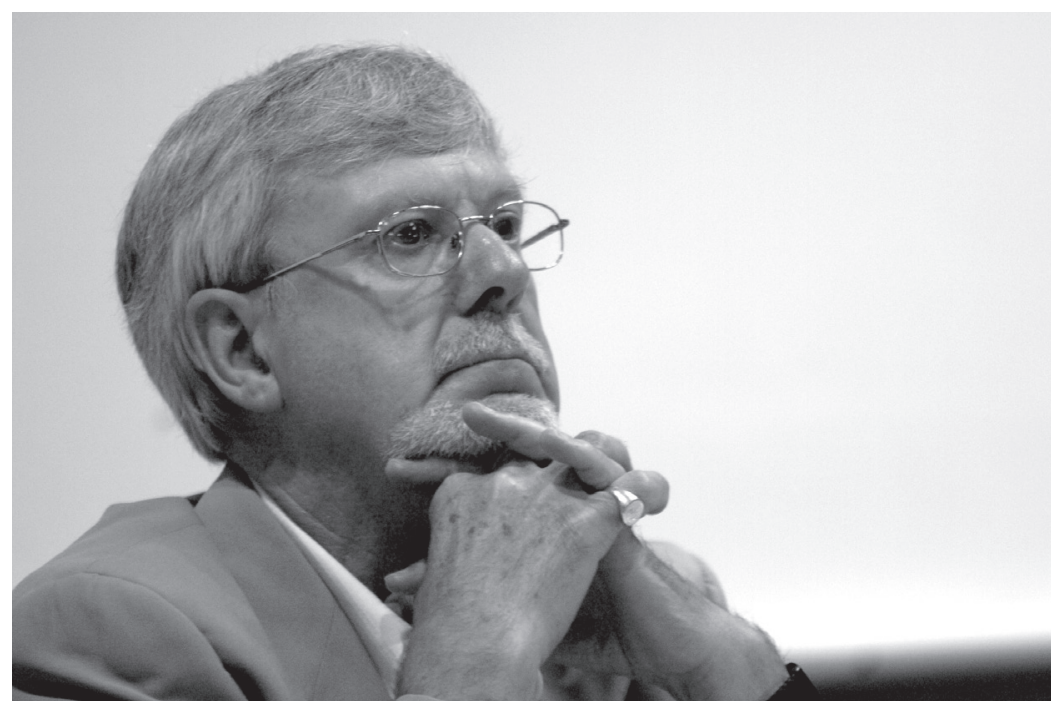

Thomas M. Robinson é um velho conhecido dos estudiosos brasileiros de Filosofia Antiga. Em primeiro lugar, porque as suas obras - especialmente aquelas dedicadas a Platão - compõem a bibliografia essencial de qualquer trabalho vinculado à área; depois, porque não foram poucas as vezes que contamos com a honra e o prazer da sua presença em terras brasileiras. A insistência em convidá-lo tantas vezes para vir ao País tem várias razões de ser e algumas devem ser destacadas aqui.

Nascido na Inglaterra em novembro de 1936, o prof. Robinson é dono de um curriculum extraordinariamente fecundo. Autor de dezenas de artigos e livros (um dos quais, o livro Plato's Psychology de 1970,

\footnotetext{
1 Entrevista conduzida por Dennys Garcia Xavier, doutor em Storia della Filosofia pela Università degli Studi di Macerata (Itália/CAPES), professor de Filosofia Antiga da Universidade Federal de Uberlândia (UFU) e Diretor Acadêmico do Núcleo de Estudos em Filosofia Antiga e Humanidades (NEFAH - UFU).
} 
posto entre os trabalhos mais importantes e impactantes do século XX em Filosofia Antiga), é membro honorário de diversas organizações científicas internacionais e de corpos editoriais de alguns dos mais prestigiosos periódicos dedicados aos Estudos Clássicos (especialmente Filosofia e Literatura Antigas) em diversas partes do mundo. Foi presidente da International Plato Society, sociedade composta por vários dos mais destacados especialistas em Platão em nível internacional e é presidente honorário da International Association for Greek Philosophy. Entre os títulos de doutor honoris causa que possui, há aquele concedido pela Universidade de Atenas, em reconhecimento aos serviços por ele prestados à cultura e filosofia Antigas. Professor visitante em dezenas de Universidades em diversos países (entre eles, Dinamarca, Inglaterra, Japão, África do Sul, México, Venezuela, Brasil, Peru e Chile), Thomas Robinson é atualmente professor emérito de Filosofia na Universidade de Toronto (Canadá).

Esses são apenas alguns dos aspectos "acadêmicos" que nos levam a solicitar continuamente a presença do prof. Robinson no País. Para além deles, mas não menos importantes do que eles, encontramse outros de natureza digamos, não técnica. De personalidade afável e acessível, ele é famoso pela sua sempre bem-humorada disposição em estar na companhia dos alunos, por onde quer que passe: fato que, naturalmente, lhe garante popularidade incomum entre os jovens estudiosos, arrebatados pelo seu carisma e pelo seu vasto conhecimento. Por que Thomas Robinson costuma dedicar tamanho tempo e atenção aos jovens? Bem, talvez a entrevista gentilmente concedida por ele para este número especial da Educação e Filosofia nos ajude a responder tal questão. De fato, como se poderá constatar, estamos diante de um estudioso fortemente convencido de que coisas consideradas boas e importantes devem ser divulgadas da maneira mais eficaz ao maior número possível de pessoas, especialmente aos jovens, visto serem terreno fecundo, ainda a ser explorado, para o empenho apaixonado ao estudo daquelas coisas... neste caso, da Filosofia Grega. Não por outro motivo, para além das suas célebres obras sobre o pensamento Antigo, o prof. Robinson tem dedicado boa parte dos seus maiores esforços na construção de um corpus 
de peças "filosóficas" de teatro - ficções nas quais filósofos e figuras insignes da cultura e do mundo grego conversam entre si, em diálogos imaginados pelo autor - que, além de nos oferecer momentos de entretenimento de altíssima qualidade, servem também como instrumento protréptico, de introdução a vários dos temas e personagens da Antiguidade Helênica. Um elemento da paidéia contemporânea, fortemente inspirado na cultura clássica, do qual não deveríamos abrir mão.

Registramos o nosso agradecimento sincero ao prof. Robinson pela entrevista. Vamos a ela.

XAVIER: Professor Robinson, conte-nos, por favor, um pouco sobre o seu primeiro contato com a filosofia. Quando e como ocorreu? ${ }^{2}$

ROBINSON: Meu primeiro encontro com a filosofia foi por volta dos meus dezessete anos, quando, como parte do meu último ano de escola de gramática grega, li o Fédon de Platão, orientado por Ronald Fox, um brilhante professor e mentor a quem tive o prazer e honra, alguns anos depois, de dedicar o meu primeiro livro, Plato's Psychology. O Fédon me parecia um trabalho de tamanha elegância e beleza de estilo que, concordando ou não com os seus argumentos, eu sabia que continuaria lendo Platão. Então, quando entrei na universidade e comecei a estudar para uma graduação em Literatura Geral e Clássica, naturalmente gravitei em torna da Filosofia Grega como meu campo de interesse especializado. E este continua o meu âmbito de estudos desde então.

XAVIER: Toda a sua carreira acadêmica desenvolveu-se no Canadá? Quais experiências você teve no exterior e qual a importância de tais experiências?

ROBINSON: Apesar de toda a minha vida de professor ter sido construída no Canadá, o meu treinamento acadêmico foi, de fato, feito na Europa. Minha primeira graduação foi na University of Durham, Inglaterra, de

2 Tradução para o português de Dennys Garcia Xavier e Kellen Ferreira de Moraes. 
1956 a 1960, onde eu aprendi com J. B. Skemp - ele mesmo um antigo discípulo de F. M. Cornford - muito sobre a maneira que em Cambridge se lê Filosofia Grega. Depois, fui para Oxford, onde, como Assistente no Jesus College, trabalhei sob a orientação de David A. Rees em uma dissertação intitulada Individual and Cosmic Soul in Plato, que foi publicada como Plato’s Psychology. Enquanto estive lá, tive o privilégio de conhecer e de ter algumas das minhas ideias rigorosamente examinadas por eles - alguns dos mais célebres acadêmicos, entre eles, ninguém menos que Gilbert Ryle, G. E. L. Owen e John Ackrill. Mas o que provavelmente mais me influenciou foi Erik Dodds. Por sua sugestão, passei o ano acadêmico de 1962-1963 na Sorbonne (Ecole des Hautes Etudes), sob a direção de André-Jean Festugière, antes de retornar a Oxford para o ano final de estudo. A experiência de Paris foi importante já que me tirou da órbita Anglo-Saxônica por um tempo e me apresentou a um estilo diferente de filosofia, e, mais especificamente, a um modo de investigar Platão que era mais neoplatônico em tom e conteúdo do que eu tinha me acostumado a ver. E, é claro, assim como os recursos da Bodleian Library em Oxford, os recursos da Bibliothèque Nationale em Paris eram magníficos para um estudo avançado. Durante esses anos em Durham, Oxford e Paris eu também aproveitei a oportunidade apresentada pelas férias de verão para viajar muito pela Europa, a maior parte do tempo como guia turístico internacional, e isso me proporcionou a chance de aprender línguas, algo que se provou profundamente importante na minha carreira. Eu já tinha aprendido Francês no colegial; pelos poucos anos seguintes, viagens e a leitura de livros me propiciaram uma grande habilidade de ler e falar em Alemão, Italiano, Espanhol, Português e Grego Moderno. O que isso me deu tem sido de valor incalculável, em termos de número e variedade de acadêmicos e estudantes ao redor do mundo que tive o privilégio de conhecer - e, como parte dessa experiência, o número de desafios acadêmicos com os quais fui forçado a lidar!

XAVIER: Você é hoje uma reconhecida autoridade em Filosofia Antiga. Como se deu o seu contato com mundo dos Antigos? 
ROBINSON: Estou certo de que há várias boas razões para se escolher viver uma vida dentro da estrutura da cultura e pensamento Grego clássicos. Minha própria escolha foi inspirada no fato de que tantas coisas fascinantes dentro do reino da filosofia - (um domínio dentro do qual eu incluo a matemática e as várias ciências, como os Gregos fizeram), as artes (especialmente o drama), teoria e prática política, e historiografia ocorreram primeiro lá. Penso gostar de aprender sobre momentos eureka; e a civilização grega parecia estar cheia deles. E é claro que a descoberta desses momentos foi sentida, em ocasiões numerosas, como um momento eureka pessoal.

Um desses momentos no reino da filosofia foi quando observei que os gregos eram aparentemente os primeiros a se envolver em uma arte que formaria efetivamente a base da filosofia, a matemática, e as várias ciências, incluindo a ciência moral: a arte que eu chamo de "generalização frutífera". Uma consciência da chamada "regra 3-4-5", por exemplo, permitiu que os egípcios construíssem pirâmides; mas foi preciso um passo crucial, e mais distante, de um pensador grego para traçar a inferência geral que, no caso de qualquer figura plana de três lados, o quadrado da hipotenusa é igual à soma dos quadrados dos dois outros lados.

Outro momento desses foi quando descobri que atomistas gregos, auxiliados apenas pela razão dos termos gerais da língua (como "espaço", "tempo", "infinito", e "movimento"), tinham conseguido criar uma teoria cosmológica e física extraordinariamente convincente. Criar uma hipótese, por exemplo, com Demócrito e Leucipo, um infinito de espaço, um infinito de tempo, e movimento eterno de um número finito de "partículas básicas" de matéria de várias formas - e alguém pode considerar não somente o mundo presente que vemos, mas uma infinidade de outros possíveis -, uma visão que chegou ao que era sem o benefício do telescópio ou microscópio, e que ainda surpreende a ciência moderna por sua plausibilidade geral.

Experimentei outro momento desse tipo quando percebi pela primeira vez que um filósofo grego tinha realmente demonstrado que há leis de argumentação - que um silogismo de fórmula "alguns X são M/ alguns $\mathrm{Y}$ são M", por exemplo, nunca pode ser válido, com o simples pressuposto de que uma condição necessária (embora não suficiente) para a validade de qualquer dedução é que no mínimo uma de suas premissas seja universal. Lembro- 
me claramente o extraordinário senso de libertação que esta percepção me trouxe; alguém poderia realmente mostrar porque vários argumentos inválidos foram assim, e que, ao seguir certas regras básicas de pensamento, alguém poderia construir argumentos que seriam no mínimo válidos, mesmo que não "palpáveis" (argumentos válidos sobre unicórnios, por exemplo).

Estes momentos são meramente aqueles que brotam imediatamente da mente; há muitos mais. E não só no reino da filosofia. Lembro-me de ser tomado pelo poder do drama grego para destacar assuntos que emocionam o coração humano. Ésquilo na maldição da Casa de Atreu e o que foi preciso para revertê-la. Sófocles na tragédia de Édipo. Sófocles na atitude moral de Antígona. Eurípides em As Troianas. E muitos mais.

$\mathrm{Na}$ área de teoria e prática política eu fui (é claro) atraído para inteira história da democracia em Atenas, e me lembro da minha surpresa quando soube pela primeira vez que alguns dos mais famosos escritores da cidade eram também os maiores críticos daquela democracia. Às vezes isso era público, como no caso de Platão. Às vezes era menos público, mas claro o suficiente mesmo assim, como no caso de Tucídides, cuja grande História da Guerra do Peloponeso li com fascinação, junto com o trabalho de seu grande predecessor Heródoto.

Em tantas frentes que me interessaram, os Gregos me ofereceram, frequentemente em prosa ou verso de qualidade brilhante, um panorama magnífico de pensamento em áreas onde eles eram com frequência os primeiros a terem articulado várias visões (na forma escrita), e eu sabia de imediato que poderia passar uma vida frutífera lendo e relendo o que eles tinham a dizer. Mas não somente lendo - me envolvendo com eles! Porque a força e vitalidade de tudo isso era tanta que demandava resposta. Admirar o pensamento grego não é simplesmente concordar com o que Eurípides, ou Sócrates, ou Platão, ou Aristóteles têm a dizer; é prestar a eles a cortesia de desafiá-los quando isso parecer apropriado. Algo que tenho tentado fazer a vida toda.

Então deixe que isso, em resumo, seja minha tentativa de responder sua pergunta. Meu contato atual com a cultura e civilização gregas tem simplesmente reforçado o sentimento que experimentei nos primeiros momentos: que há aqui algo tão magnificamente expresso que vale a pena ler e reler em detalhes somente pela sua forma, e, ao mesmo tempo, tão 
importante e desafiador em suas afirmações que vale a pena uma resposta cuidadosa e detalhada. E isso, para mim, tem valido uma vida.

XAVIER: Entre os filósofos antigos, Platão parece ter recebido a maior parte dos seus esforços investigativos. Qual o motivo desta preferência, professor? Qual a importância de Platão nos dias de hoje?

ROBINSON: Por que eu tenho passado tanto tempo da minha vida estudando Platão em particular? Provavelmente porque gosto da natureza dialógica da sua mente. Ao dizer isso, levo em consideração todos os que alegam encontrar "uma doutrina" em Platão, com a qual podem concordar ou discordar, em parte ou em sua totalidade. Minha própria visão é a de que ele foi um "pesquisador" filosófico por uma vida inteira, e que ele sentia que a melhor técnica para filosofar era usar a forma de diálogo.

Isso não significa que alguém não possa encontrar certos compromissos gerais através dos diálogos - o essencialismo, por exemplo, o funcionalismo, e a imortalidade da alma. Mas Platão sente-se livre o tempo todo para examinar cuidadosamente (e re-examinar) qualquer coisa que para ele pareça importante - inclusive os compromissos citados. Seu essencialismo, por exemplo, tem uma tensão "transcende" em diversos dos diálogos centrais, mas essa característica parece ter desaparecido, ou ser de qualquer modo não mais uma parte vital de seu argumento, quando ele escreve as Leis. E, significativamente, depois de uma vida escrevendo sobre a alma, ele ainda, aparentemente, em idade avançada, não sabe se o corpo do sol "empurra" de fora, ou o "puxa" de dentro, ou se relaciona de alguma outra forma que é completamente misteriosa. Isto é uma honestidade intelectual que aprecio.

Mas e quanto às suas "doutrinas não-escritas", pode-se perguntar? Sobre isso eu sempre senti a necessidade de ser cauteloso. Que ele era, enquanto envelhecia, cercado de pessoas na Academia que apontavam para a direção da construção de um sistema filosófico (eminentemente Aristóteles e Espeusipo) parece claro o suficiente, e que ele se envolvia seriamente com eles o tempo todo é algo de que dificilmente se poderá duvidar. Entretanto (e sem surpresa, eu diria, dada a natureza dialógica de sua mente), muito pouco desse material "sistemático" terminava nos diálogos, e os poucos 
que terminavam eram frequentemente "ajustados" por razões mais bem conhecidas por ele mesmo (a distinção entre o uno e a díade indefinida, por exemplo, algo muito discutido na Academia, aparece como uma distinção entre limite e ilimitado no Filebo). Ou, para colocar de modo diferente, ele era mais que disposto a aprender com os construtores de sistema entre seus discípulos, especialmente enquanto envelhecia, mas, invariavelmente, continuava com o seu próprio caminho dialógico, incorporando em vários momentos em seu pensamento um pouco da "doutrina" então em voga, mas também reservando o direito de sujeitá-la a uma contínua avaliação, do Parmênides em diante, sempre re-examinando a Teoria das Formas. Se formos falar da "doutrina" platônica presente em tudo isso, é a doutrina do essencialismo; a natureza e detalhes do essencialismo, vale dizer, que estão para sempre abertos a avaliação contínua. $\mathrm{O}$ mesmo pode ser dito da sua crença na alma: que ela exista e é imortal é um princípio básico; entretanto, exatamente como ela se relaciona com o corpo e qual parte dela passou a ser imortal é algo que ele estará, até o fim de sua vida, re-avaliando.

Platão ainda é importante? A resposta dependerá muito da postura filosófica pessoal do indivíduo. Para muitas pessoas, eu inclusive, as grandes ideias de Platão (a Teoria das Formas, funcionalismo, os argumentos para a imortalidade da alma, a suposta natureza problemática da democracia) permanecem eloquentes, mas inconclusivas como argumentos. Mas são elementos aos quais se deve dedicar. E é por isso que ele deveria continuar a ser lido e continuará sendo.

Mas igualmente importante, me parece - algo que nós todos podemos aprender, se concordarmos com ele ou não em qualquer tópico em particular - é a abordagem dialógica dele em relação ao mundo. Não se pode ler a República, por exemplo, sem ler em detalhes o seu trabalho final sobre política, as Leis, que revela um homem que mudou sua concepção de modos sobremaneira significativos em uma variedade de tópicos importantes, incluindo a natureza da justiça. Muito disso, creio, é o resultado de uma vida inteira de pensamento dialógico. $\mathrm{O}$ mesmo pode ser dito sobre suas visões, através de vários diálogos, da relação entre a opinião verdadeira e o conhecimento (estou pensando em particular no Mênon, na República e no Teeteto), ou sobre se a alma realmente é composta de três partes ou não: o filósofo é o pesquisador, destemido para mudar sua mente 
se boas razões se apresentarem para que o faça, e disposto a mudar sua mente ainda mais se outras razões exigirem isso.

XAVIER: Você teve uma experiência "televisiva" com a filosofia. Qual a importância desse tipo de trabalho? É possivel falar de filosofia para tal público?

ROBINSON: Sempre acreditei que, se alguém considerar algo profundamente importante, ele tem a obrigação de divulgar isso ao maior público possível. Então, quando oportunidades de falar para públicos de rádio e televisão sobre o que nós aprendemos com filosofia em geral e filosofia grega, em particular, se apresentaram a mim, sempre me aproveitei delas. Trata-se de um desafio falar sobre tópicos que frequentemente soam difíceis de entender para um público que sabe pouco ou nada sobre eles, mas não há desafio mais intimidador, eu acho, do que a tarefa de milhares de professores de filosofia em universidades quando eles se deparam com uma sala de aula com alunos em que metade se especializou em algo bem diferente (por exemplo, física), e estão presentes no curso somente para completar uma graduação secundária em algum tópico dentro daquela estranha e remota área, "Humanas". O que é ensinar senão a tentativa de mostrar aos entediados ou céticos que o assunto em questão é eloquente e fascinante se eles forem persuadidos a dar um pouco da sua atenção?

Dito isso, eu devo admitir que a televisão é algo muito peculiar, com seu desejo de histórias de dez segundos de informação. Mas há exceções a essa regra, não somente no caso da $T V$ Ontário, que uma vez me deu seis períodos de meia hora do tempo da televisão (sem interrupções de comerciais!) para entrevistar seis dos melhores acadêmicos de filosofia moral do mundo sobre tópicos de interesse ético atual. $\mathrm{O}$ mesmo pode ser dito da Canadian Broadcasting Corporation, que uma vez me cedeu cinco horas no ar (novamente sem interrupções de comerciais) para falar sobre a cultura e civilização gregas e depois prosseguiu publicando as palestras como um trabalho de faculdade intitulado The Greek Legacy. Eu sei, entretanto, que sou afortunado em relação a isso; muitos outros países, eu tenho observado, não são tão generosos com seu tempo no rádio e televisão para considerar as coisas da mente. 
Esse tipo de coisa tem um impacto? É difícil saber. Eu só posso dizer que ambos os programas sobre os quais acabei de falar alcançaram uma audiência de aproximadamente um terço de um milhão de pessoas; cada um foi reapresentado várias vezes e The Greek Legacy esgotou. Os acadêmicos estão perdendo seu tempo fazendo esse tipo de coisa? Alguns podem achar que sim. Mas pelo que experimentei, sou otimista o suficiente para pensar que a verdade pode ser outra.

XAVIER: De fato, você criou um novo (e interessantíssimo) modo de falar sobre filosofia... as suas peças filosóficas de teatro. Conte-nos um pouco sobre elas, professor.

ROBINSON: Estou convencido, há muito tempo, de que a filosofia grega se provaria atrativa para muitas pessoas, incluindo aquelas fora dos confins das universidades, se pudessem ser apresentados a ela de uma maneira interessante e estimulante. E uma dessas formas, penso, é por meio do drama; em particular o drama sobre como grandes figuras do cenário filosófico e literário da Grécia podem ter interagido umas com as outras se elas tivessem se conhecido. Uma característica da vida grega - os Jogos Olímpicos que aconteceram a cada quatro anos - me ofereceu um mecanismo maravilhoso para fazer isso.

Sabemos que, entre os muitos tipos de pessoas que assistiram aos Jogos - e às vezes participaram deles - estavam os literati da Grécia. Sófocles, por exemplo, era um lutador quando jovem; e também Platão. Então o que precisei fazer foi pesquisar a data particular de um dos Jogos (por exemplo, os Jogos Olímpicos de 456 a.C.), descobrir quem provavelmente pode ter estado lá - e então colocá-los lá! Eu podia então imaginá-los reunindo-se todas as noites depois do pôr-do-sol para uma noite de degustação de vinho e discussão, em que eles passariam alguns minutos falando sobre os vários esportes que tinham visto aquele dia, mas, então, rapidamente mudar para assuntos de interesse mais eloquentes pra eles, nada menos que o trabalho uns dos outros, especialmente o trabalho em progresso.

Cada peça consiste em três atos (um para cada noite dos Jogos) e é, com efeito, uma Olimpíada da Mente, em que os maiores intelectos da 
Grécia disputam um com o outro, ambos seria e alegremente (a presença de filósofos como Parmênides e Sócrates e comediógrafos como Crátinos e Aristófanes - sempre pronto para furar qualquer balão aparentemente superinflado na sua vizinhança - assegura isso). Desde 2006 eu completei dezesseis peças desse tipo; a mais recente, situada nos Jogos de 404, se sairá razoavelmente bem como um exemplo do que estou falando.

Nos Jogos de 404, que acontecem somente três meses depois da grande derrota de Atenas por Esparta, tenho no palco, por várias vezes, Sócrates; três dos seus jovens protegidos que ele traz com ele (Xenofonte, Platão e Aristipo); o historiador Tucídides; o comediógrafo Aristófanes; os sofistas Hípias e Trasímaco; o físico Hipócrates; a amante do jovem Aristipo (a hetaera Laís); e a amante do jovem Platão (a hetaera Archaenasa). Mulheres casadas não eram permitidas nos Jogos, como todo mundo sabe; mas "outras" mulheres eram...

Como já se pode imaginar, com essa configuração particular de pessoas inteligentes e articuladas no palco (incluindo Laís e Archaenasa, que se valem de seus cérebros para usar sua beleza) há alguns confrontos políticos e filosóficos, e alguns comentários amargos sobre porque e como Atenas perdeu a guerra. Mas há uma boa quantidade de comédia também, quando Aristófanes em particular faz piada sobre o jovem apaixonado Platão, e Hipócrates oferece um discurso irônico sobre o amor como patologia. Isso também dá uma oportunidade para indivíduos de ler pequenas passagens do que eles estão trabalhando; Tucídides, por exemplo, tem a chance de ler a sua História da Guerra do Peloponeso, enquanto outros recitam passagens de dramas do recente falecido Eurípides, incluindo $A s$ Bacantes e Ifigênia em Táuris.

A minha esperança é que as peças sirvam de estímulo e sejam úteis ou como padrão de desempenho teatral para o público em geral ou como leitura de peças por estudantes como parte de, digamos, seminário introdutório para vários cursos universitários. A peça de 476, por exemplo, que apresenta Parmênides, Heráclito e Zenão, entre outros, poderia servir de introdução ao curso de filosofia pré-socrática. As peças de 456 e 440, que apresentam Péricles e Aspásia, Címon, Sófocles, Zenão e o jovem Sócrates, entre outros, poderia servir como introdução ao curso sobre a Era de Péricles. A tetralogia de peças de 424 a 404, apresentando Sócrates, 
Aristófanes, Eurípides, Sófocles, Demócrito, Trasímaco, Tucídides, Cleon e Alcibíades, entre outros, poderia servir como uma introdução para cursos sobre filosofia, drama e política do final do século V. E as três peças do século IV poderiam servir como uma introdução aos cursos sobre - entre outras coisas - a teoria política e filosófica de Platão e Aristóteles. Nenhuma das peças, é claro, foi pensada como um substituto para um dado curso; o objetivo é aumentar o interesse nos temas, e satisfazer os alunos, fazendo com que o curso no qual estão ingressando valha seu tempo e energia.

Até agora, fico feliz em dizer, as coisas estão dando certo como eu esperava. Minha primeira peça, The Diaries of Socrates, foi apresentada na Grécia (Samos), Estados Unidos (Oakdale, NY), Venezuela (Caracas) e China (Beijing). A segunda, Plato's Monologues, foi apresentada na Espanha (Benasque). E a terceira, The Other Olympians (Parte Um), na qual a figura central é Parmênides, foi apresentada recentemente no local da antiga cidade de Elea, onde Parmênides passou a sua vida como professor. Então estou me sentindo encorajado.

XAVIER: Você veio ao Brasil algumas vezes. O que acha dos estudos em Filosofia Antiga desenvolvidos por aqui? Estamos num bom caminho? O Brasil sediará o Simpósio da International Plato Society em 2016...

ROBINSON: Sim, eu tive o prazer de apresentar conferências no Brasil algumas vezes. Em 1971 em São Paulo, Campinas, Rio de Janeiro e Porto Alegre. Em, 2002, 2004 e 2006 eu dei palestras na Universidade Católica de São Paulo. E mais recentemente, em 2009, eu dei palestras em Uberlândia, Belo Horizonte, São Paulo e Natal, juntamente com uma série de oito palestras na Universidade de Brasília que foram recentemente publicadas como As Origens da Alma. Em tudo isso, me considero muito afortunado, já que tenho tido a chance de observar a vitalidade do cenário brasileiro na área de Filosofia Grega. Duas coisas em particular me influenciaram: o entusiasmo de ambos, faculdade e alunos, pelo assunto em tantos dos lugares que eu visitei, e a qualidade dos periódicos acadêmicos e programas de pesquisa na área. Naturalmente, aqueles que passei a conhecer melhor são os de São Paulo e Brasília, dada a quantidade de tempo que passei em cada lugar. Mas também me impressionei com a 
vitalidade dos estudos gregos em muitos outros lugares, notadamente Rio de Janeiro, Belo Horizonte, Campinas, Porto Alegre e Uberlândia. Esta crescente realização acadêmica foi um fator significativo, estou certo, para o Brasil ser eleito como o cenário para a reunião trienal da International Plato Society em 2016. E estou igualmente certo de que a reunião fará muito mais para reforçar o lugar dos Estudos Gregos no perfil acadêmico do País.

XAVIER: Professor, deixe uma mensagem para os estudantes brasileiros. Muitos deles estudam Filosofia Antiga por meio dos seus livros e ficariam felizes em ouvi-lo.

ROBINSON: Eu gostaria de expressar meu grande encorajamento a todos os alunos brasileiros de Filosofia Grega para perseguirem o que estão fazendo com paixão. Um interesse modesto produzirá resultados modestos; um interesse apaixonado, combinado com pesquisa meticulosa e atenção, produzirá estudiosos que colocarão a disciplina em um novo patamar de excelência. O Brasil merece nada menos que isso; e espero que os alunos de hoje cresçam com esse desafio e garantam que ele seja vencido.

\section{INTERVIEW WITH THOMAS M. ROBINSON FOR THE COMMEMORATIVE EDITION OF THE JOURNAL EDUCAÇÃO E FILOSOFIA}

XAVIER: Please, professor, tell us a little about your first contact with philosophy. When was that? What was it like?

ROBINSON: My first encounter with philosophy was at the age of seventeen, when, as part of my final year of grammar-school Greek, I read Plato's Phaedo under the tutelage of Ronald Fox, a superb teacher and mentor to whom I had the pleasure and honour, some years later, of dedicating my first book, Plato's Psychology. The Phaedo seemed to me 